\title{
Microwave Synthesis of a Porous Metal-Organic Framework, Zinc Terephthalate MOF-5
}

\author{
Jae Yong Choi, Jeo Kim, Sung Hwa Jhung, ${ }^{\dagger}$ Hye-Kyoung Kim, ${ }^{\dagger}$ Jong-San Chang, ${ }^{+{ }^{\star}}$ and Hee K. Chae \\ Department of Chemistry Education, Seond National University, Seoul151-748, Korea. E-mail: hkchael@snuackr \\ ${ }^{\dagger}$ Research Center for Nanocatalysts, Korea Research Institute of Chemical Technology, P.O. Box 107, Yusung, \\ Daejeon 305-600, Korea. "E-mail: jschang@krict.re.kr \\ Received November 9,2005
}

Key Words : Microwave synthesis, Organic-inorganic hybrid material, Metal organic-frameworks, MOF-5

\begin{abstract}
Organic-inorganic porous hybrid materials are currently of great interest and importance for the novel coordination structure, relatively facile preparation, special properties and potential practical applications. ${ }^{1.2}$ Recent studies have been focused on the design and synthesis of porous materials which possess a very low density, high surface area and specific functionality. Among these materials, metal organic frameworks (MOFs), originally coined and intensively studied by Yaghi $e t a l$. are crystalline and well-defined structures, consisting of metal ions or oxo-bridged metal clusters linked by organic carboxylates. ${ }^{2 a-c}$ In particular, a series of MOF-5s have open metal frameworks with high Langmuir surface areas $\left(1000-4500 \mathrm{~m}^{2} / \mathrm{g}\right)$ and thermal stability. ${ }^{2 \mathrm{k} .3}$ These
\end{abstract} porous "organic" zeolites are mimicking the frame and properties of the zeolite, and thus many potential industrial applications arise from the promising properties of these high-surface materials. The structural architecture of MOFs can be extended to the real zeotype frameworks by Ferey et al. who showed the MTN type structure from chromium oxo cluster ion and terephthalate, very recently. ${ }^{4}$ In general, MOFs can be synthesized by a slow diffusion method diffusion of amine into a solution containing metal salt and organic carboxylic acid - for weeks or a solvothermal reaction technique for hours. ${ }^{2}$ Recent literature, however, revealed that it is not easy to prepare MOF-5 with a high surface area by both methods. ${ }^{5}$ Resulting MOF nanocrystalline materials ${ }^{\text {sa }}$ and space group $F m-3 m$ like MOF-5 materials $\mathrm{s}^{\text {sb }}$ had Langmuir surface areas of 727 and $572 \mathrm{~m}^{2} / \mathrm{g}$, respectively, but these figures are far below the reported value of $2900 \mathrm{~m}^{2} / \mathrm{g}$ by Yaghi. ${ }^{20}$ Furthermore, both groups noticed that their MOFs slowly tend to decompose in moisture and acid, thus this instability may limit their practical applications.

On the other hand, a microwave irradiation method has been studied in the syntheses of not only organic molecules ${ }^{6}$ but also inorganic materials. ${ }^{7-11}$ More recently, microwaveassisted synthesis of inorganic materials requiring several days for their crystallization has attracted much attention. This technique provides synthesis methods of porous materials with saving the reaction time within a few minutes ${ }^{\gamma}$ and offering phase selectivity ${ }^{9}$ and facile morphology control. ${ }^{10}$ Very recently, some of us recently reported that microwave technique can be well applied to the rapid synthesis as well as phase selective crystallization of porous hybrid solids including MIL-77, MIL-100 and MIL-101. ${ }^{11}$

Here we describe the first result on the microwave synthesis of MOF-5, $\mathrm{Zn}_{4}(\mathrm{O})(\mathrm{BDC})_{3} \cdot$ guest molecules $(\mathrm{BDC}=1,4-$ benzenedicarboxylate) with a high surface area, as named MW MOF-5 (Microwave MOF-5). MW MOF-5 was synthesized in $N . N$-diethylformamide (DEF) using microwave irradiation. Equimolar amount of $\mathrm{H}_{2} \mathrm{BDC}(1.57 \mathrm{mg}, 0.60 \times$ $\left.10^{-2} \mathrm{mmol}\right)$ and zinc nitrate tetrahydrate $(1.50 \mathrm{mg}, 0.60 \times$ $\left.10^{-2} \mathrm{mmol}\right)$ in a DEF $(0.6 \mathrm{~mL})$ were place in a $10 \mathrm{~mL}$ tube. The tube was sealed with a robber septum and placed in a microwave oven (Discover, CEM, maximum power of 300 W). The resulting mixture was heated at $95^{\circ} \mathrm{C}$, held for 9 $\mathrm{min}$ and then cooled to room temperature. The colorless crystalline materials $(2.10 \mathrm{mg}, 27 \%$ yield) were obtained by centrifuging, washing with $N, N$-dimethylfornamide (DMF, $3 \times 5 \mathrm{~mL}$ ) and drying briefly in the air.

The morphology of MW MOF-5 was studied by scarning electron microscopy (SEM) after gold deposition. The SEM image shows three dimensional cube-like microcrystals with the length of $2-4 \mathrm{~mm}$ as illustrated in Figure 1. Its morphology was consistent with the previous result which was obtained from slow diffusion with addition of $\mathrm{H}_{2} \mathrm{O}_{2}$, even though SEM image of MOF-5 produced by $\mathrm{H}_{2} \mathrm{O}_{2}$ is not clear. $^{\text {sa }}$

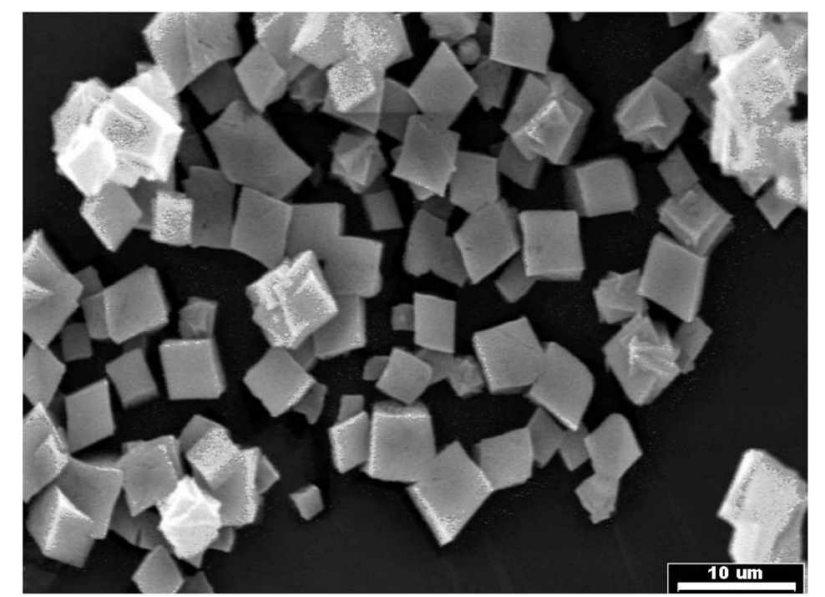

Figure 1. The SEM image of MW MOF-5 obtained from microwave irradiation at $95^{\circ} \mathrm{C}$ for $9 \mathrm{~min}$. 


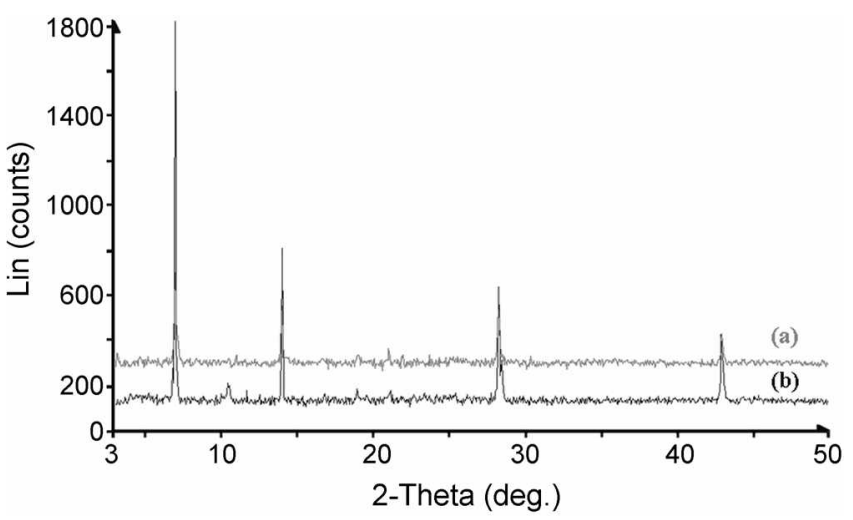

Figure 2. XRD patterns of MOF-5 prepared by the hydrothermal reaction (a) and microwave irradiation (b).

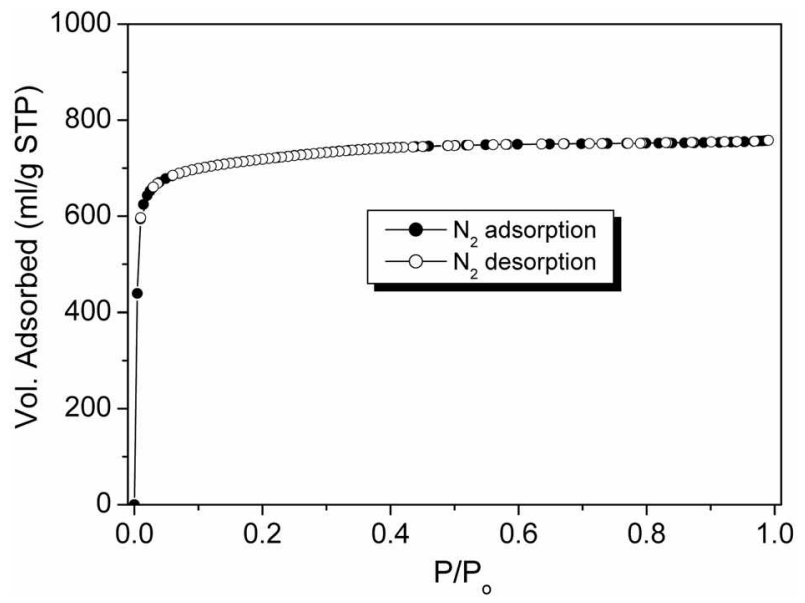

Figure 3. Adsorption-desorption isotherms of nitrogen over $\mathrm{MW}$ MOF-5 after evacuation at $200^{\circ} \mathrm{C}$ for $3 \mathrm{~h}$.

Figure 2 shows the XRD pattem of as-synthesized MW MOF-5 under microwave irradiation. The XRD pattem of the sample obtained from microwave irradiation was well matched with that of as-prepared MOF-5 by hydrothemal reaction as well. MW MOF-5 is also characterized by the vibrational stretching frequencies of $\mathrm{C}-\mathrm{O}$ of $\mathrm{BDC}$ and $\mathrm{DEF}$ that are 1605 and $1648 \mathrm{~cm}^{-1}$ using a FT-IR (Perkin-Elmer System $2000, \mathrm{KBr}$ pellet, $4000-400 \mathrm{~cm}^{-1}$ ), respectively, which values are consistent with those of MOFs. ${ }^{2 a c}$

Themal behavior of the as-prepared MW MOF-5 was investigated using themogravimetric analysis (TGA). The TGA profile reveals two weight changes around 200 and $475{ }^{\circ} \mathrm{C}$. The first gentle slope of weight loss ( $\mathrm{ca} .36 \%$ ) between 100 and $200^{\circ} \mathrm{C}$ attributes to the solvated molecules that are the mixture of non-volatile DEF (bp $176^{\circ} \mathrm{C}$ ) and water (calcd $40 \%$ ). The second major loss of $\mathrm{ca} .39 \%$ accounts for the framework decomposition of organic carboxylates (calcd 38\%). Overall themal stability is similar to the previous result. ${ }^{2 a}$

To confirm the pemanent porosity, we obtained the $\mathrm{N}_{2}$ adsorption isotherm of MW MOF-5 using a gas sorption analyzer (Micromeritics, ASAP 2000) after careful evacu- ation at $200{ }^{\circ} \mathrm{C}$. The $\mathrm{N}$, adsorption isotherm reveals a typical type-I behavior, as plotted in Figure 3. Fitting the BET and Langmuir equations to the resulting isotherm $\mathrm{N}_{2}$ gives estimated surface areas of $\mathrm{S}_{\mathrm{BET}}=2869 \mathrm{~m}^{2} / \mathrm{g}$ and $\mathrm{S}_{\mathrm{Lang}}=$ $3060 \mathrm{~m}^{2} / \mathrm{g}$, respectively, which are close to the reported value of $2900 \mathrm{~m}^{2} / \mathrm{g}$ by Yaghi. ${ }^{2 \mathrm{a}}$ Extrapolation of $\mathrm{t}$-plot yields an available micropore volume of $0.94 \mathrm{~cm}^{3} / \mathrm{g}$.

In summary, we have first shown that MW MOF-5 is synthesized efficiently within several minutes and its physicochemical and textural properties are very similar to those synthesized by conventional hydrothermal heating. Thus mass production of MW MOF-5 can possibly be applied to practical applications. Current work is focused on investigating the role of concentration, molar ratio of metal and ligand, temperature and time on the synthesis of MW MOF-5.

Acknowledgement. This work was supported by Grant No. R01-2003-000-10667-0 from the Basic Research Program of the Korea Science and Engineering Foundation and the Korea Ministry of Science and Technology for the Institutional Research Program (KK-0603-F0). The authors would like to thank Dr: Y. K. Hwang and Dr. J.-S. Hwang for their helpful discussions, and Mr. J. W. Yoon for technical assistance.

\section{References}

I. (a) Kickelbick, G. Angew, Chem. Int, Ed, 2004, 43, 3102, (b) Ferey, G; Mellot-Draznieks, C.; Serre, C.; Millange, F. Acc. Chem. Res. 2005, 38, 217. (c) Nicole, L.; Boissiere, C.; Grosso, D.; Quach, A.; Sanchez, C. J. Mater, Chem. 2005, 15, 3598.

2. (a) Li, H.; Eddaoudi, M.; O'Keeffe, M.; Yaghi, O. M. Nature 1999, 402, 276. (b) Yaghi, O. M.; O'Keeffe, M.; Ockwig, N. W; Chae, H. K.; Eddaoudi, M.; Kim, J. Nattre 2003, 423, 705. (c) Chae, H. K.; Siberio-Perez, D. Y.; Kim, J.; Go, Y.; Eddaoudi, M.; Matzger, A. J.; O'Keeffe, M.; Yaghi, O. M. Natme 2004, 427, 523. (d) Dybtsev, D. N.; Chun, H.; Yoon, S. H.; Kim, D.; Kim, K. J. Ani. Chem. Soc. 2004. 126. 32.

3. Eddaoudi, M.; Kim, J.; Rosi, N.; Vodak, D.; Wachter, J.; O'Keeffe, M.; Yaghi, O. M. Science 2002, 32, 468.

4. Ferey, G; Mellot-Draznieks, C.; Serre, C.; Millange, F.; Dutour, J.; Surble, S.; Mirgiolaki, I. Science 2005, 309, 2040.

5. (a) Huang, L.; Wang, H.; Chen, J.; Wang, Z; Sun, J.; Zhao, D.; Yan, Y. Microporots Mesoporotis Mater. 2003, 58, 105. (b) Panella, B.; Hirscher, M. Adr. Mater: 2005, 17, 538.

6. Larhed, M.; Moberg, C.; Hallberg, A. Acc. Chem. Res. 2002, 35, 717.

7. Park, S.-E.; Chang, J.-S.; Hwang, Y. K.; Kim, D. S.; Jhung, S. H.; Hwang, J.-S. Catal, Simey: Asia 2004, 8, 91.

8. Jhung, S. H.; Yoon, J. W.; Hwang, J.-S.; Cheetham, A. K.; Chang, J.-S. Chem. Mater. $2005,17,445$.

9. Jhung, S. H.; Chang, J.-S.; Hwang, J. S.; Park, S.-E. Mfroporous Mesoporonts Mater: 2003, 64, 33.

10. Hwang, Y, K.; Chang, J.-S.; Park, S.-E.; Kim, D. S.; Kwon, U. K.; Jhung, S. H.; Hwang, J.-S.; Park, M. S. Angew. Chem, Int, Ed. $2005,45,556$.

I1. (a) Jhung, S. H.; Lee, J.-H.; Chang, J.-S. Bull. Korean Cheni. Soc. 2005, 26, 880. (b) Jhung, S. H.; Lee, J.-H.; Forster, P. M.; Ferey, G.; Cheetham, A. K.; Chang, J.-S. Chem. Eur J. 2006, 12, 7699. (c) Jhung, S. H.; Lee, J.-H.; Serre, C.; Ferey, G.; Chang, J.-S. Adt Mater, accepted (2006). 